\title{
Apartado 3
}

Propuestas y planes de actuación sobre centros históricos

\section{segundo premio}

\section{CENTRO BARRIAL CARBONERAS DE LA COMPAÑIA DEL GAS}



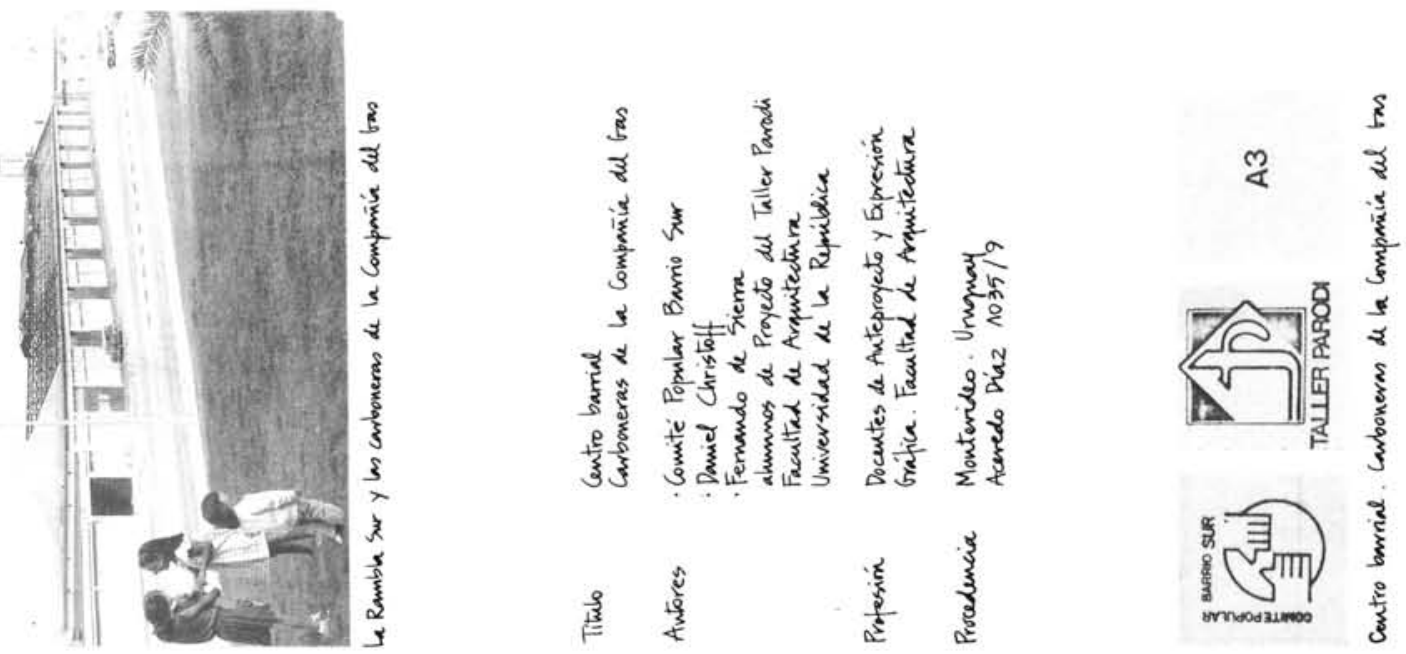

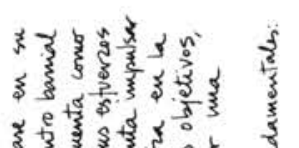

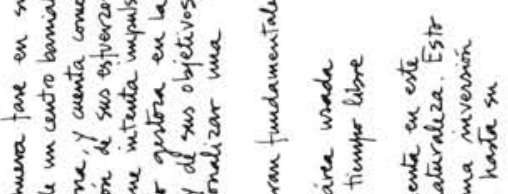

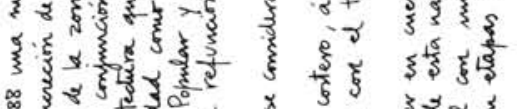

एक

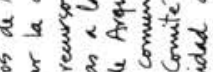

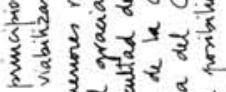

< 2 व

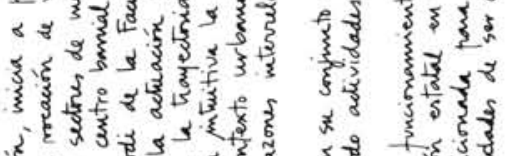

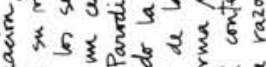

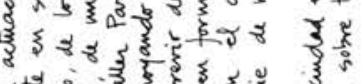
₹

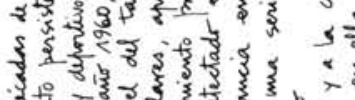

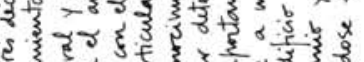

व

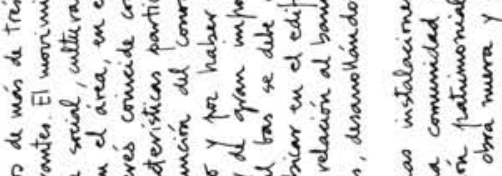

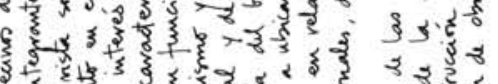

子

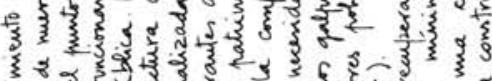

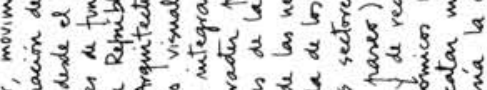

दूरेड

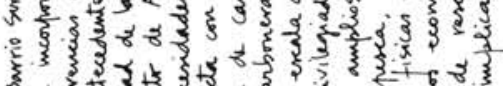

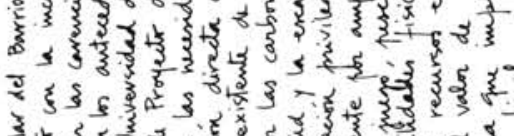

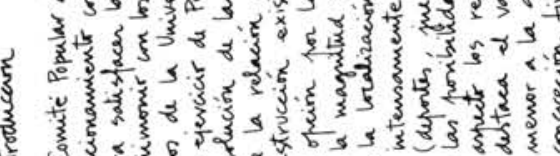

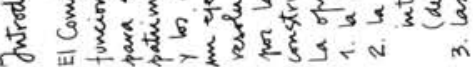

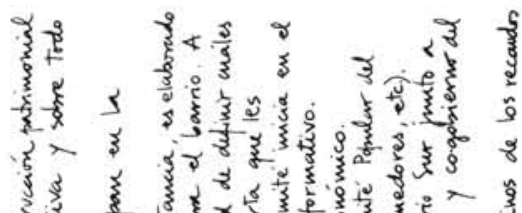

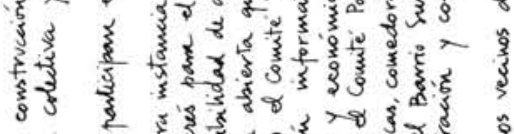

娄

ई है ई

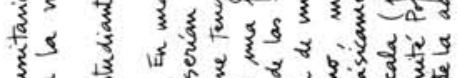

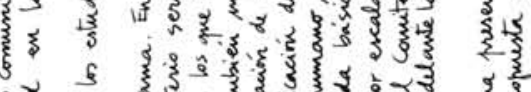
2. 3 3 है

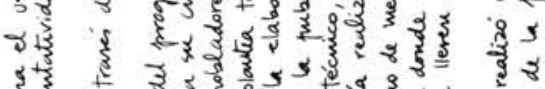

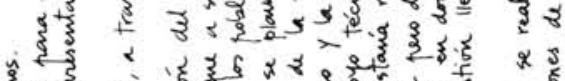
और औ व

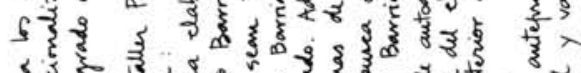

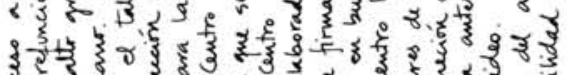

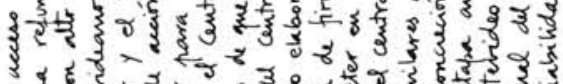

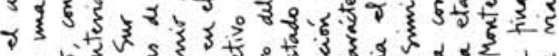

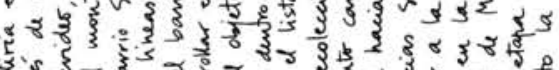

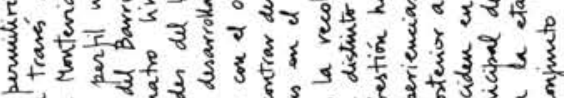

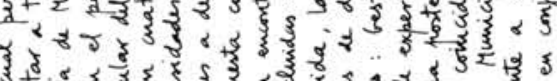

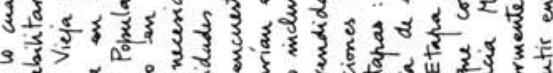
है 3.

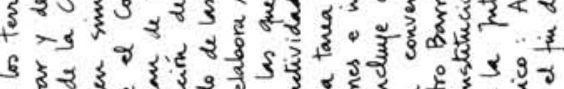

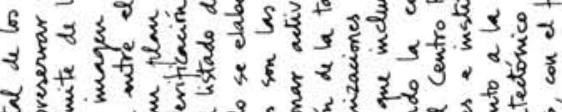

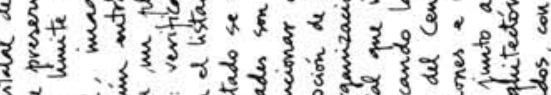

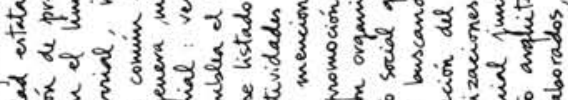
3.द है। 35 वां एक है$\mathrm{Nm}$
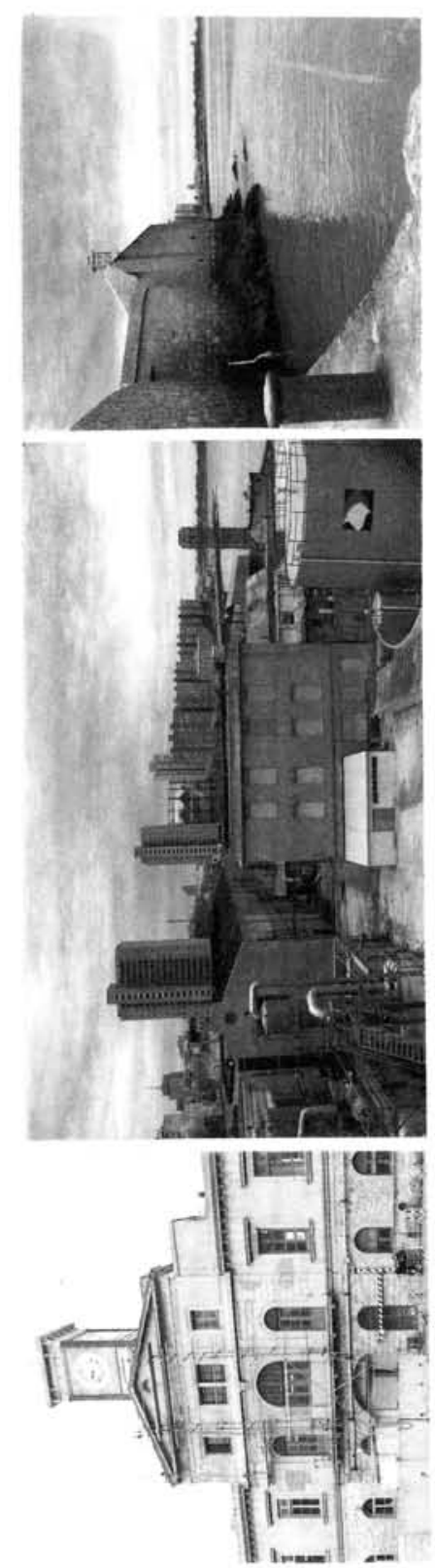

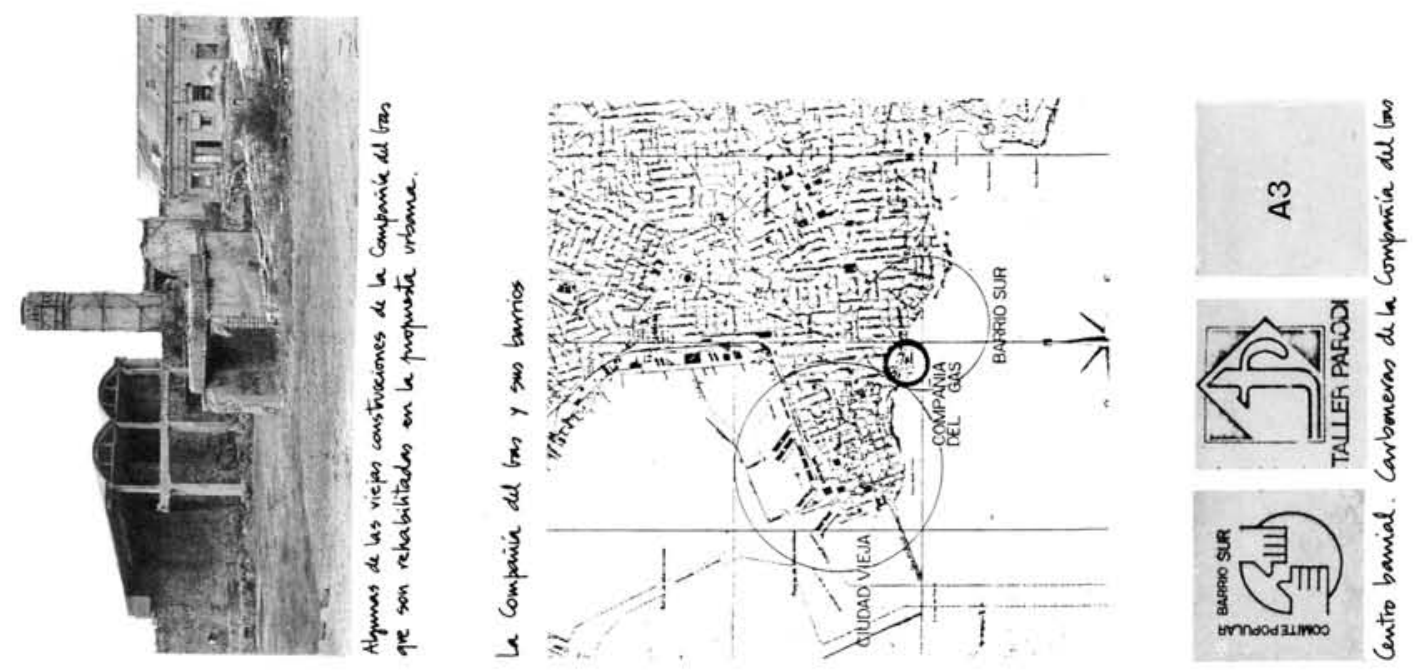

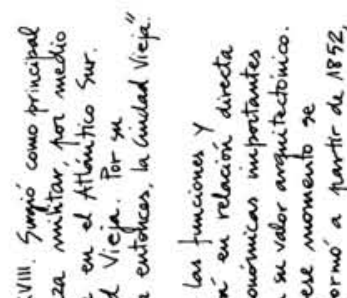

Hys

thy

IIII)

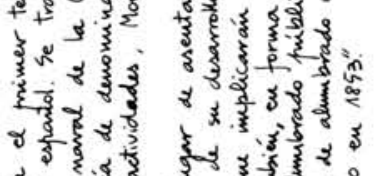

और

और

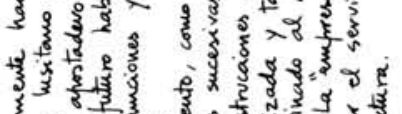

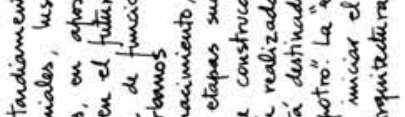

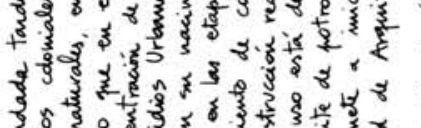

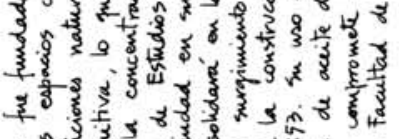

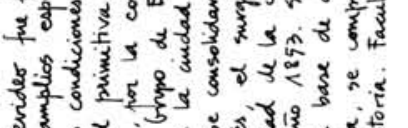

年

范

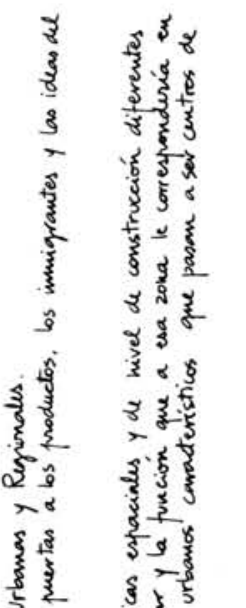

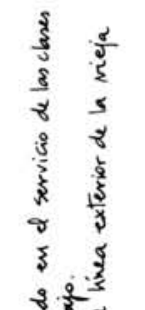

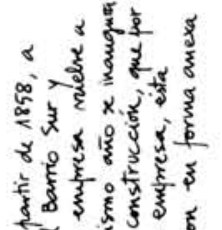

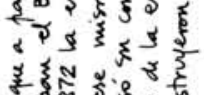

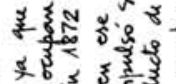

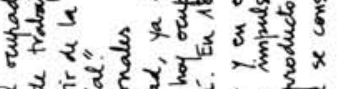

สิ ईके है

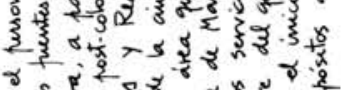

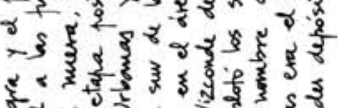

व.3

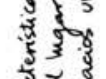

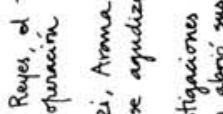

हु่ว

हैं

ส

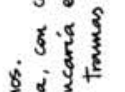

3.

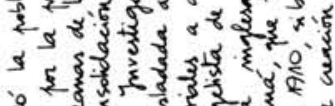

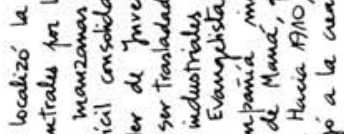

5 रु

रा ₹ु

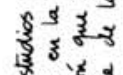

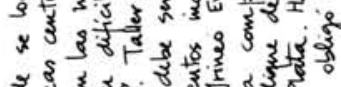

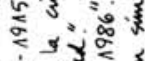

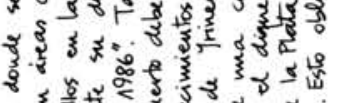

ว

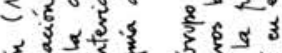

ईद

है

3.

औरते

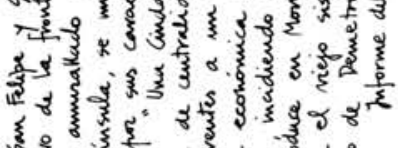

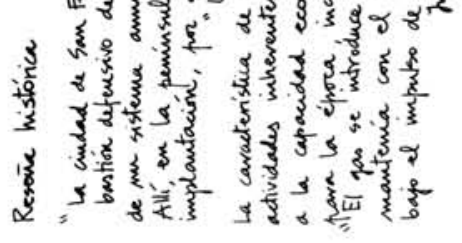

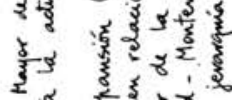

i. दू है

उ. ชิ

ช 3 ชิ

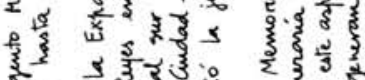

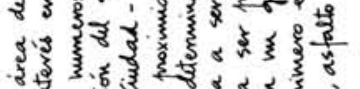

व.

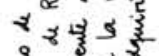

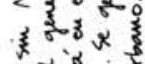

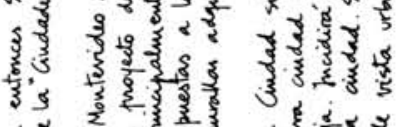

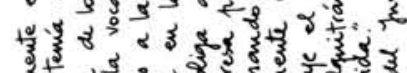

3.

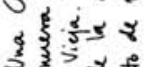

3.

ई.

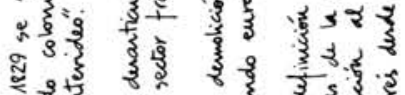

है

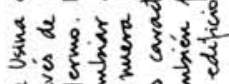

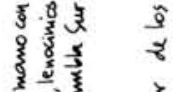

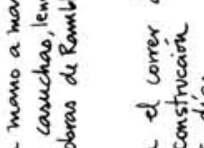

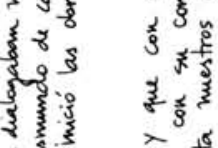

की ริ

की

ई

के

है

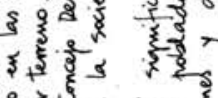

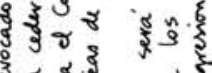

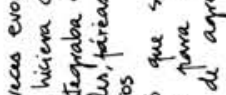

(3)

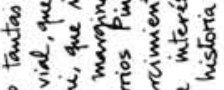

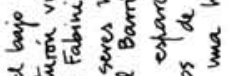

13

ई.

ई ईदे है

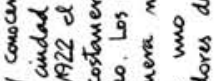

टरक

ह क्वे

इक级

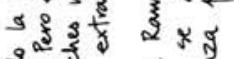

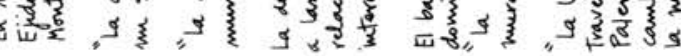




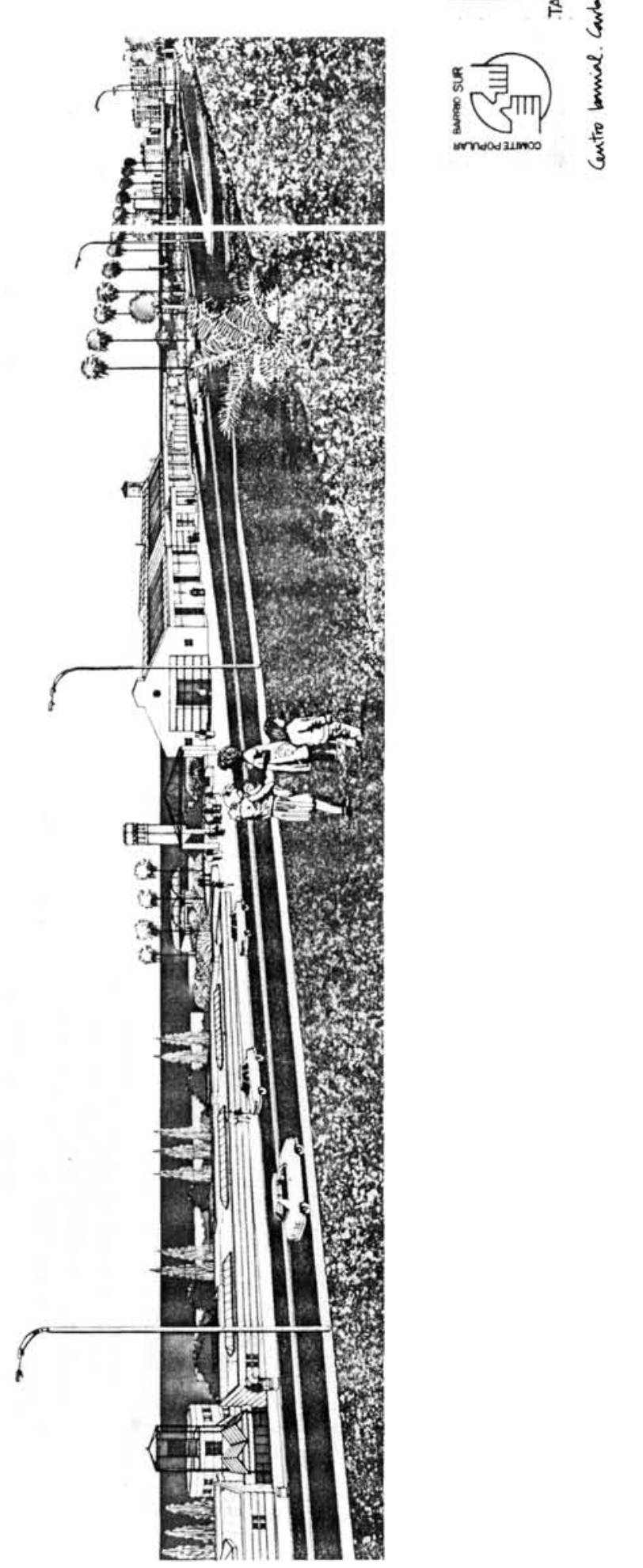



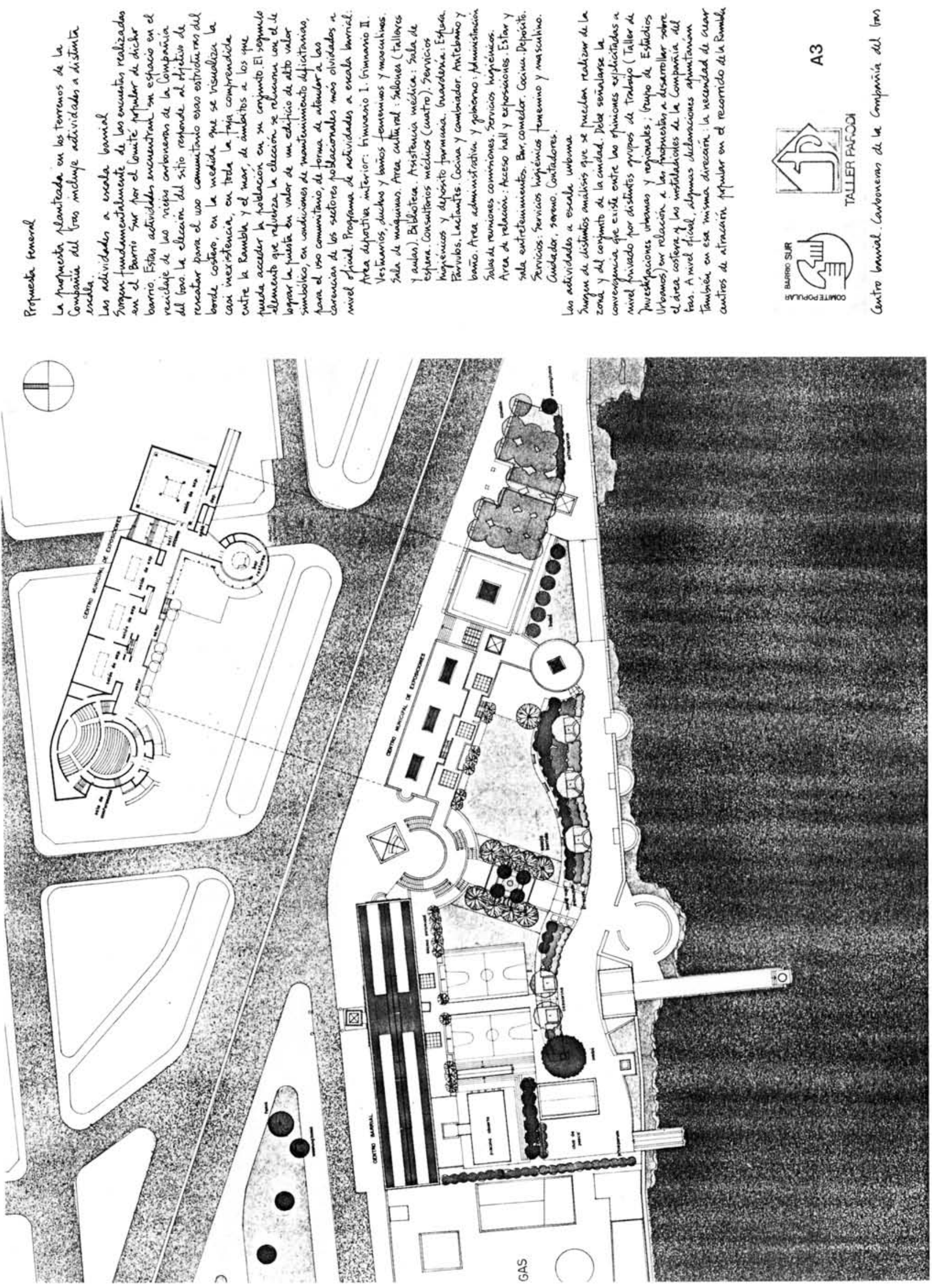


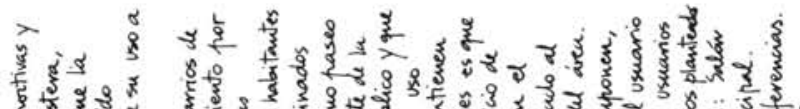

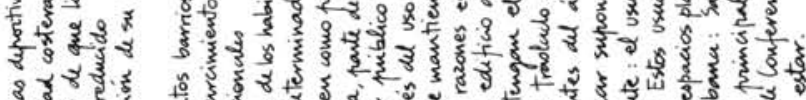

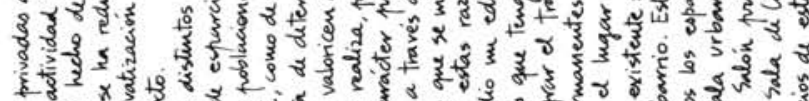

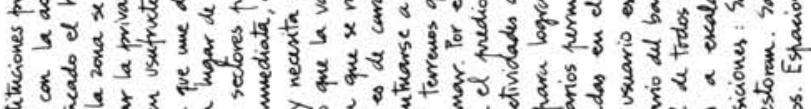

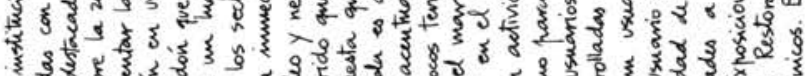

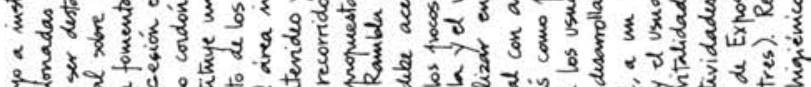

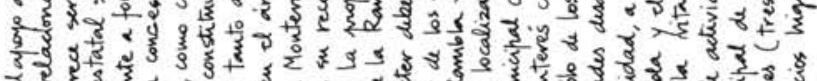

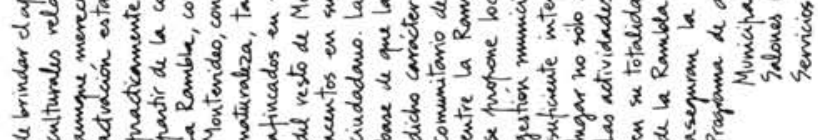
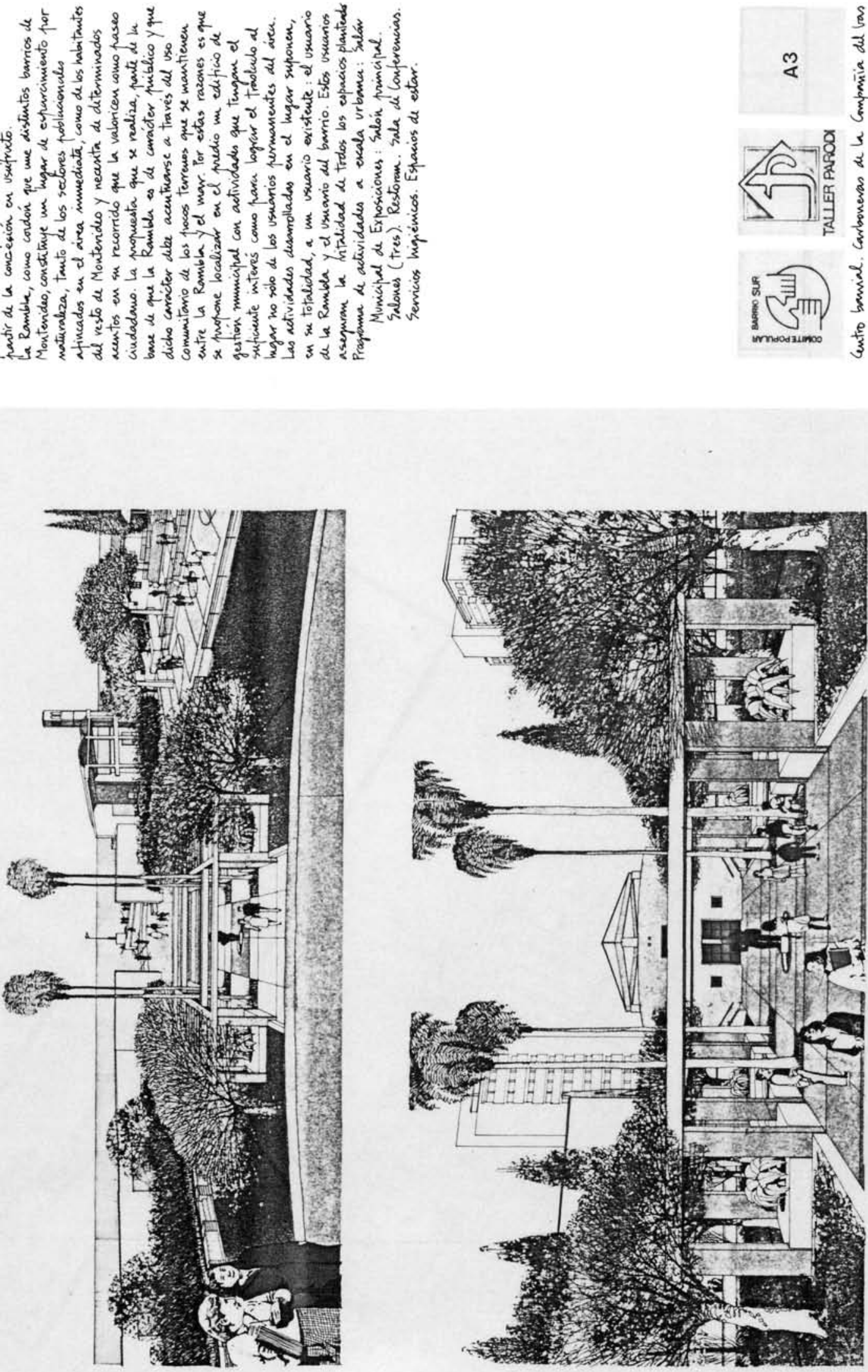
Informes de la Construcción, Vol. 41 n. ${ }^{\circ} 402$, julio/agosto, 1989
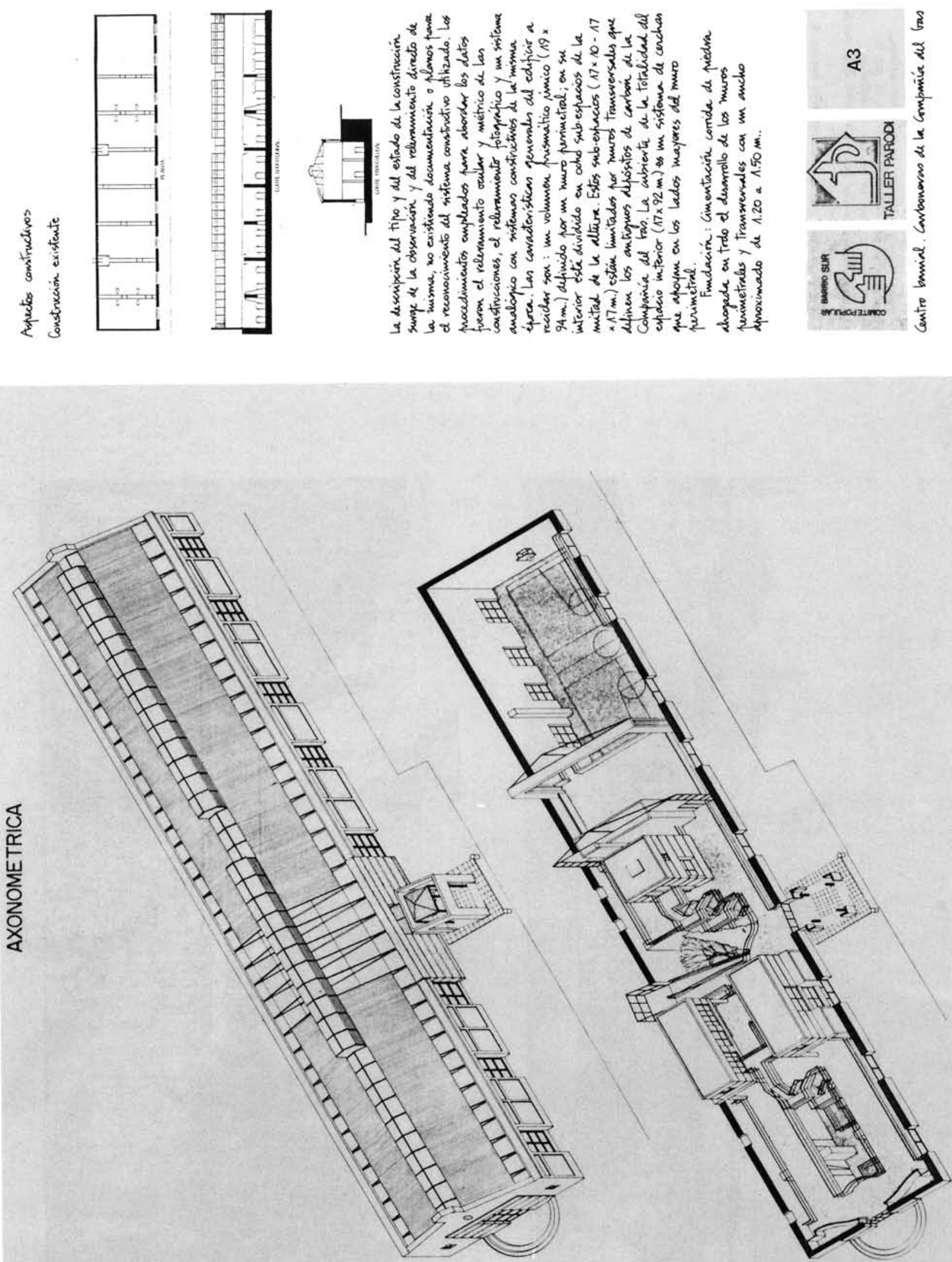

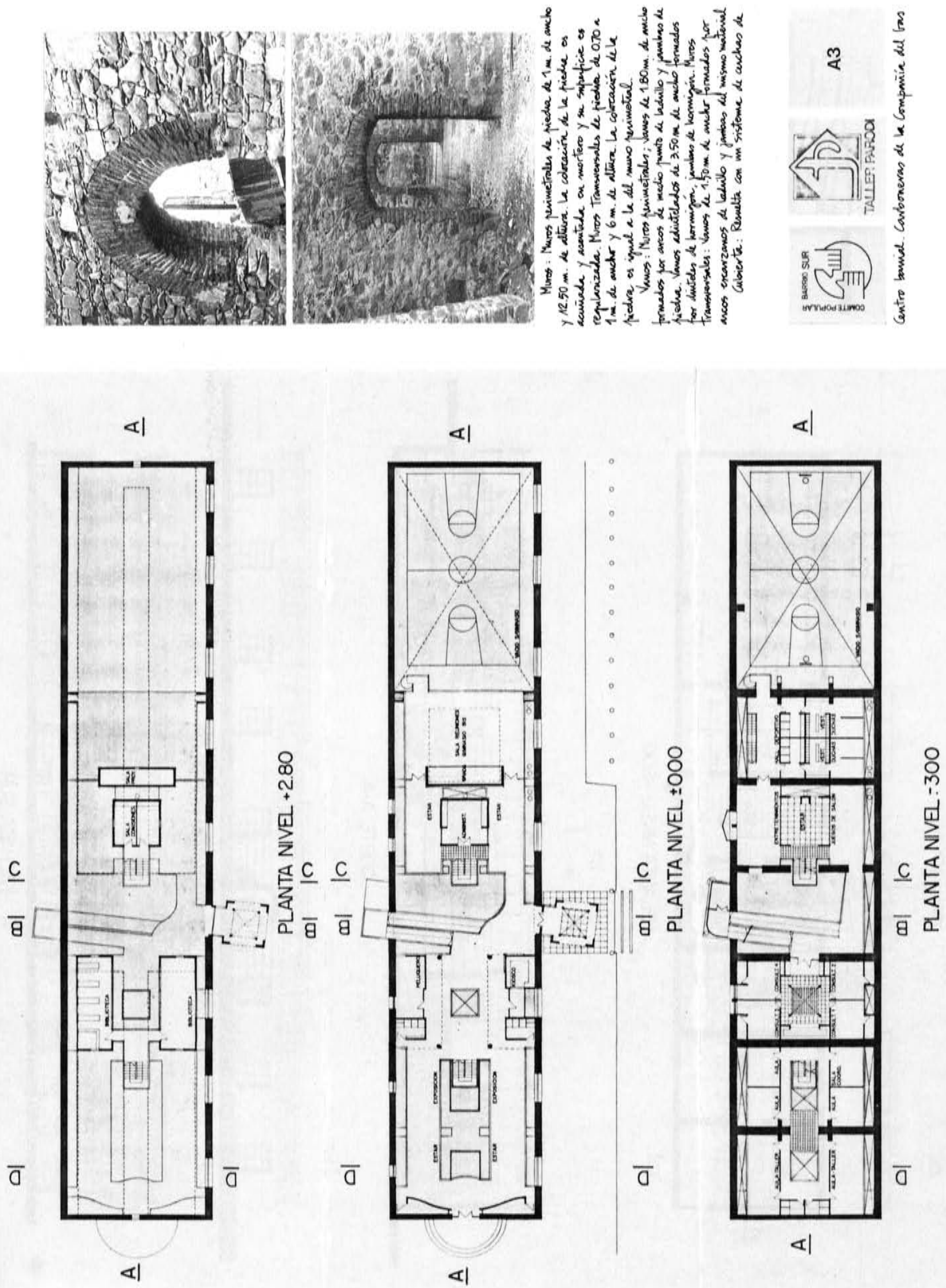

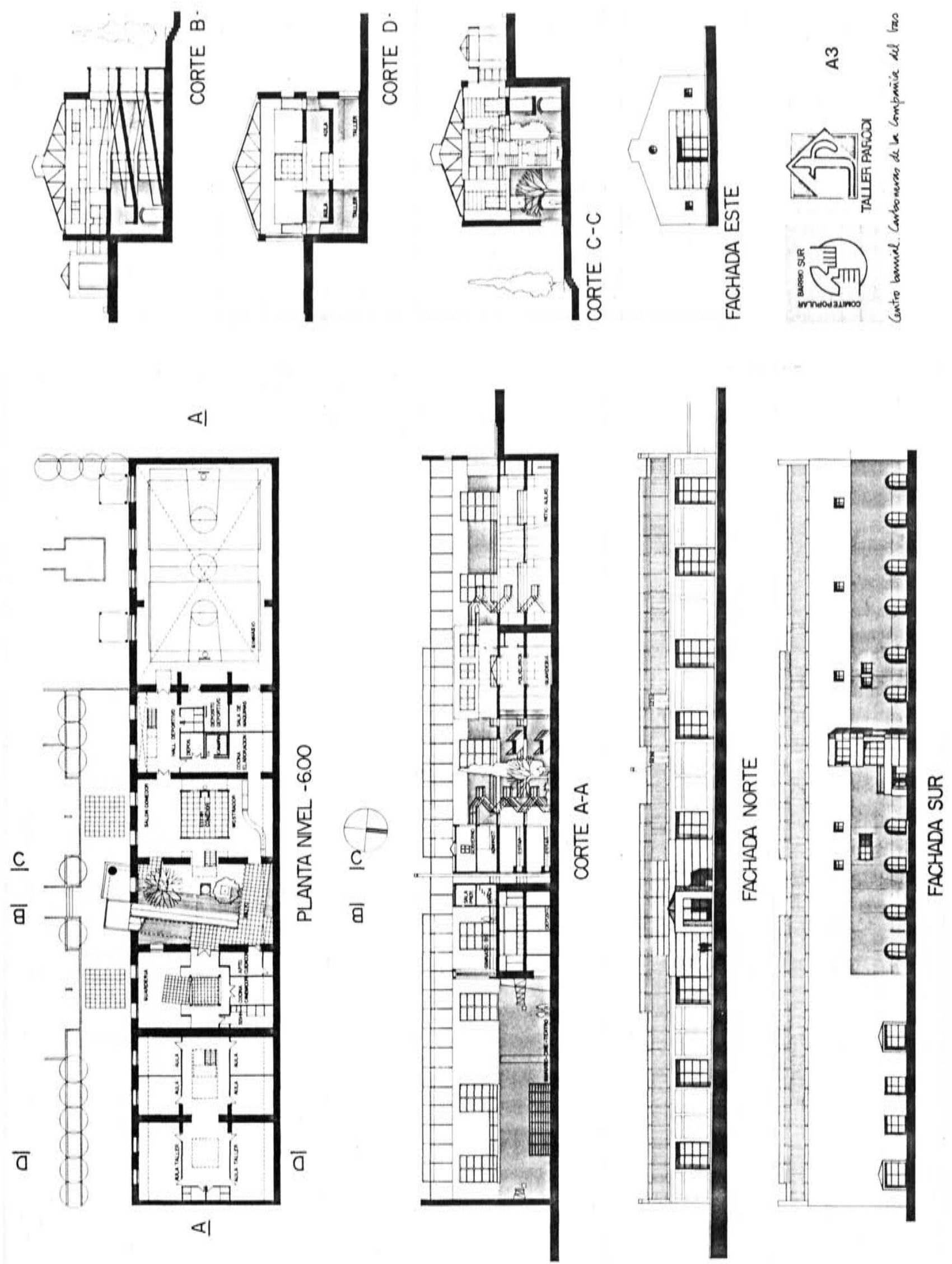
Informes de la Construcción, Vol. 41 n. ${ }^{\circ}$ 402, julio/agosto, 1989
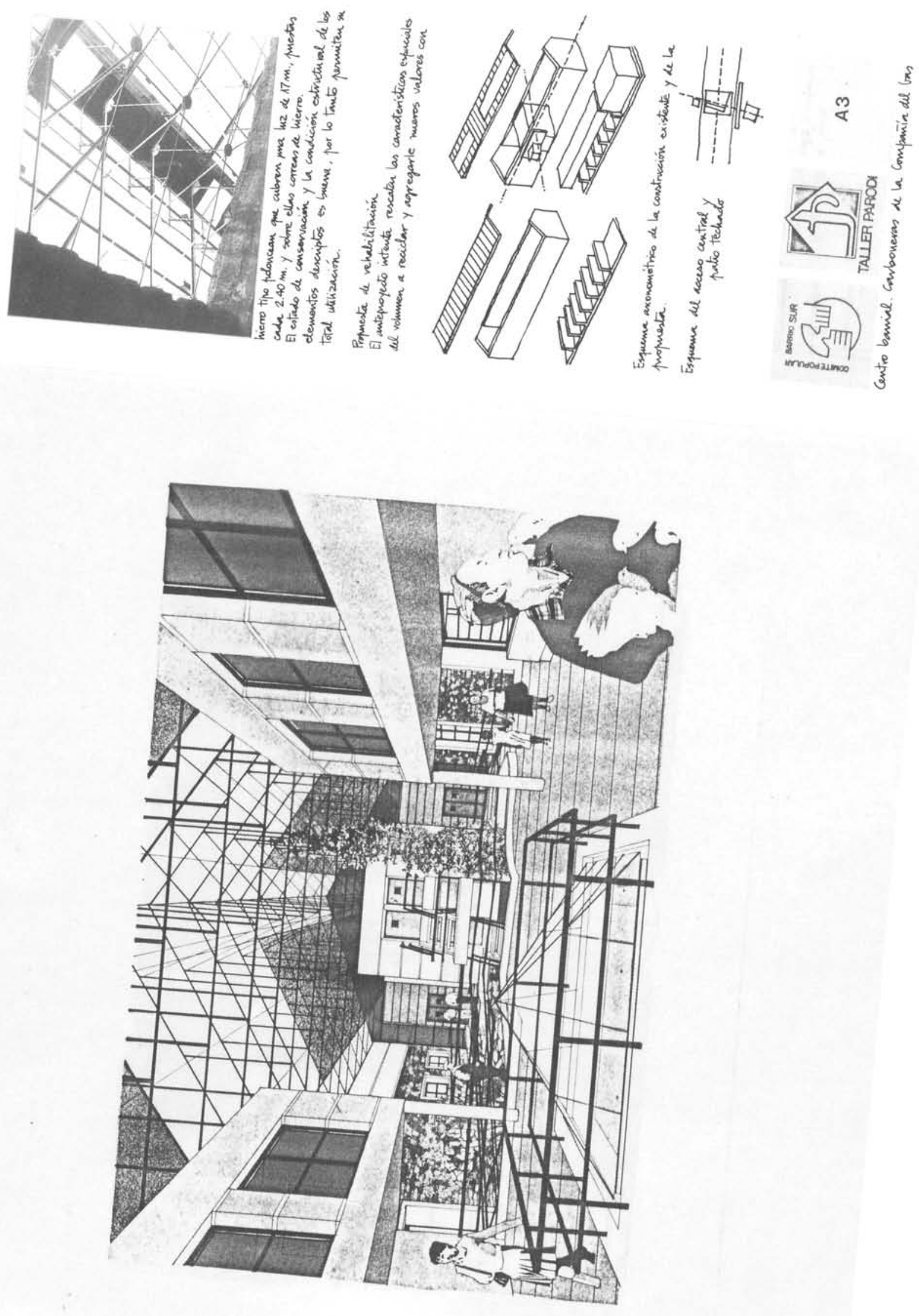

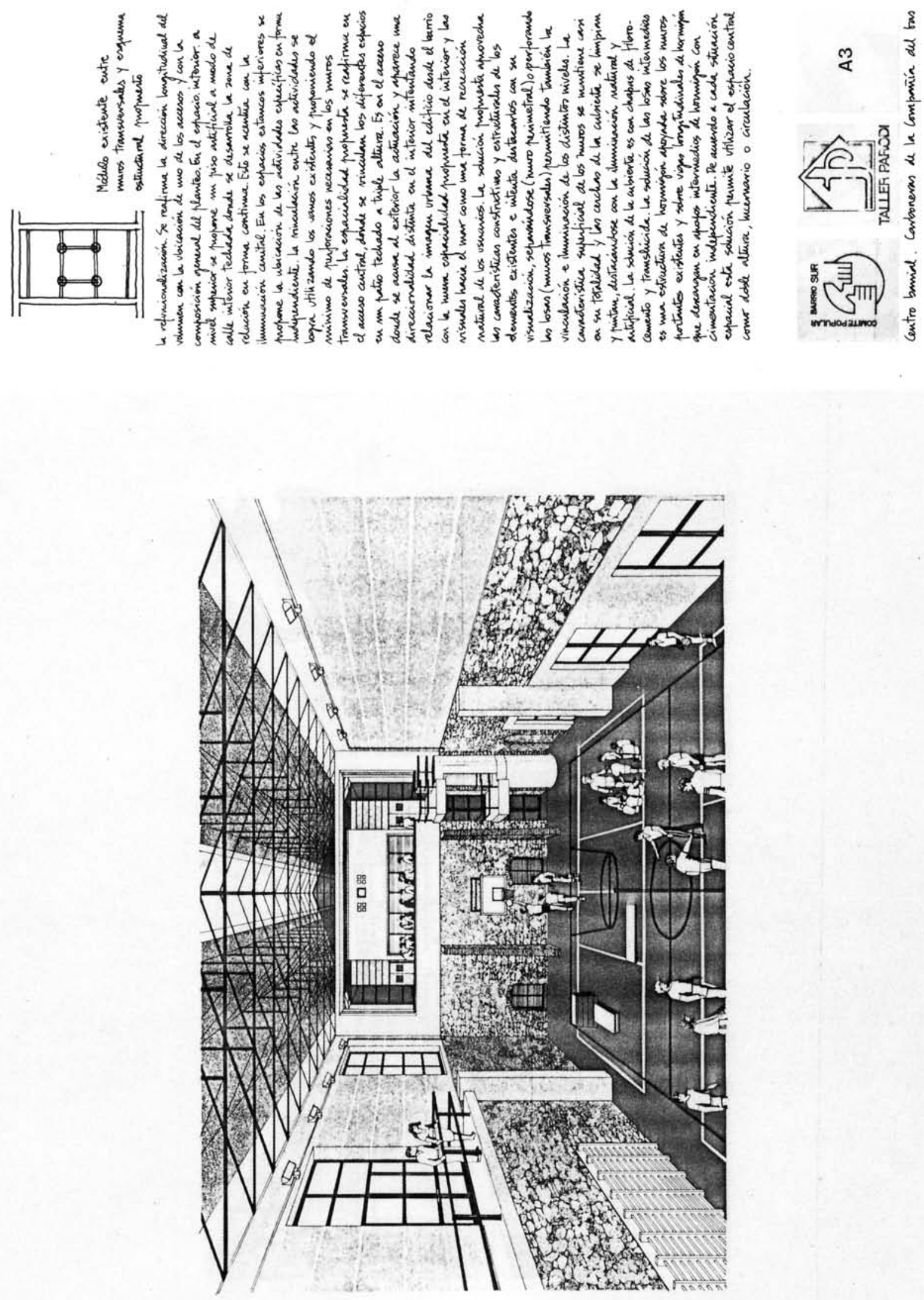